\title{
Analysis of Pragmatic Failure and Pragmatic Ability Formation in English Teaching
}

\author{
RuifengLuo \\ Foreign Languages Department of Sichuan Vocational and Technical College, Sichuan, China \\ School of English Studies of Shanghai International Studies University, Shanghai, China
}

93448900@qq.com

\begin{abstract}
Key Words: Cross-cultural communication,Pragmatic failure,Pragmatic competence, English teaching
\end{abstract}

Abstract: In cross-cultural communication, there is always a pragmatic failure. The paper analyzes the reasons for pragmatic failures and suggests some measures to cultivate students' pragmatic competence in daily English teaching in order to do some contribution to English learning.

\section{Introduction}

With the deepening of the globalization, communication between people is becoming more and more frequent, people from different social and cultural religious background for various needs start to communicate, and thus the intercultural communication is formed. Cross-cultural communication refers to communication between native speakers with the non-native speakers and also refers to the exchanges with any society, language and culture background (Hu Wenzhong, 1994). The purpose of this paper is to analyze the students' pragmatic failures in cross-cultural communication problems and propose how to cultivate pragmatic competence on the basis of the author' experience and feeling of years in teaching English.

\section{Pragmatic Failures}

In the early 1980s, the study of pragmatic failure began to start. In 1983, English linguist Jenny Thomas published the book Cross-Cultural Pragmatic Failure, and made definition of pragmatic failure classification. His English pragmatic failure can be divided into language of pragmatic failure and social pragmatic failures. The former refers to the mistake for not conforming to native English language speakers' habits, misusing English expression or not understanding English correct expression and according the set of semantic structure of their mother tongue into English. The latter refers to the mistake for not understanding the cultural background difference and the choice of errors of language form.In the same year, Leech, G (1983) also pointed out that pragmatic-language errors are mainly on linguistic and pragmatic failures and the social pragmatic failures are mainly on the interface.In fact, it can be said that a comprehensive national circumstances. Pragmatic failure is due to the different sides of history, culture, customs in which in cross-cultural communication each side tries to speculate from their own cultural perspective so that cognitive differences are produced, resulting in pragmatic failure. Thereafter, pragmatic failures had undergone an unprecedented development.

Since the term "pragmatic failure" was introduced to China, scholars conducted rigorous exploration in this respect, and also provided a rich precious opinion. He Ziran(1998)pointed out in his book A Survey of Pragmatics, that pragmatic failure is the error of not achieving full communication effect in verbal communication. Qian Guanlian (2002) also pointed out in the book Pragmatics in Chinese Culture that pragmatic failure is defined as one that the speaker uses the symbols in the language communication correctly, but unconsciously violates the interpersonal norms, social statute, or out of time space, and does not pay much concern to the partner.So the nature of the errors is called pragmatic failure. It is well known that pragmatic failure is the error which occurs in unsatisfactory effect in people's verbal communication, which does not originate from the grammatical error of itself but from speaking in wrong way, or not meeting the customary 
expression, or putting it out of place.(He Ziran,1998)

\section{The Causes of Pragmatic Failure}

There are many causes of pragmatic failure. First of all, Chinese students are lack of understanding of western values and culture. In eastern and western cultures, there are understanding differences of behavior way, appellation differences, values, and social factors (such as talking time and space position, the identity of the object or social status, etc.)(He Ziran, 1997). People with different cultural norms system usedifferent communication strategies and therefore communication misunderstandings are produced naturally ( $\mathrm{Li}$ Gang, 1999).From the point of view of second language acquisition, mother tongue' pragmatic knowledge and pragmatic rules of negative transfer can also lead to pragmatic failure. So Lu Wenhua and Lu Jianyi(1993) argued that as the students' mother tongue' pragmatic rules and cultural factors have been learned and have become their way of thinking and the code of conduct,they often interfere with learning and using foreign languages. This migration contains positive transfer and negative transfer, and the negative transfer of pragmatic failure may appear. In language pragmatic level, when the speakers is trying to translate their native language into the target language,and to express it as identical as possible on the semantic expression, they can not imagine the great differences between the east and the west on the syntactic structure, grammatical rules and unequal,resulting different pragmatic meanings via different readings. So Chinese students often wrongly write the so-called Chinglish, such as convenient noodles, big movie, etc. In social pragmatic level, because of social distance, the relevant authority, evaluating the relationship between rights and obligations and the cross-cultural error produced in the evaluation process, often affects the linguistic choice, resulting in pragmatic failure.

From the point of view of teaching, the traditional foreign language teaching attaches excessive importance to the cultivation of students' language ability, not paying due attention to students' language awareness,pragmatic consciousness and the cultivation of intercultural communication ability. In China's colleges and universities,foreign language teaching position is not accurate that education seems to hold conservative attitude in which foreign language teaching has always remained the same, namely introducing languages only rather than thought. (Li Zheng \&Hu Chunhua , 2005) If in foreign language teaching, to learn languages is not to learn its thought,it is very difficult to contain real acquisition in the rich cultural connotation behind the language. Now many colleges and universities' measure of the standard English is not testing how much of the pragmatic failures, but is through CET-Four, CET-Six, TEM-Four andTEM-Eight,which are English level examinations of various degrees set up by Chinese Ministry of Education. And foreign language level is associated with future career, which most of the students feel hard to avoid deviation. They won't pay much consideration to pragmatic failure in communication. At the same time, the current teaching materials do not have contents which are conscious,well planned and can fully reflect the pragmatic rules of English and Chinese language and cultural differences. Teaching materials and classroom discourse often lack authenticity, and teachers and students put excessive emphasis on metalanguage itself that the emergence of pragmatic failures are inevitable.

For example,an important US visitor came to one Chinese college accompanied by a group of patient and kind leaders and teachers. The hosts gave considerate service to that visitor by guiding him around the college,telling its foundation,history and future development.The visitor felt very satisfactory and said to the Chinese hosts when departing:"Thank you for your considerate entertainment." One of the Chinese hosts responded happily that it is my duty,thinking that the counterpart will smile.However,the visitor became angry because in English, duty has the meaning of having to do something rather than doing something willingly.But in China,this is the polite respond which can heighten audience's status and lower the speaker.In English speaking countries, if someone praises one, the person being praised will say "thank you" and someone addresses thanks to the one,the person should say "you are welcome".So it is the cultural 
differences leading to pragmatic failure.

\section{Cultivation of Pragmatic Competence}

Based on Bachman(1990), pragmatic competence is not an external power, an additional ability, and is different from the grammar knowledge and discourse.It is the interaction between linguistic knowledge such as grammar, discourse knowledge and the ability of successfully implementing the target language communication.He Ziran (1997) said: "not only the pragmatic knowledge of English should be taught, but should be included in the teaching plans. Because of the importance of pragmatic content,in English teaching,it is as important as the content of the grammar, vocabulary, etc."

How to effectively cultivate students' pragmatic competence is to pay much attention to the development of pragmatic awareness first. Teachers should not only emphasize the language itself, but also strengthen the guidance of language use and make students to understand discourse rules' differences and the difference between eastern and western different cultural backgrounds. And students, after be imbued with a corresponding knowledge, should put the pragmatic knowledge in the concrete practice and use it effectively. The consciousness of the students themselves to improve the pragmatic competence must strive to improve and without strong consciousness, can't students combine taught knowledge with practical application very well.

The content of teaching and examination mode is in need of improvement. The students should correctly understand a kind of culture and understand the differences between two culture systems.Knowing not enough cultural information intake is obviously not enough, so we must enrich students' culture knowledge. This makes the traditional teaching content be changed that specific implementation is added in the setting of courses and more literature, cultural background, social customs, and social relations should be given to them that students can learn more and absorb them more efficiently. The reform of examination is an important content. Besides examining students' language ability, pragmatic competence should also be taken as a measure of an important part of the students’ English level.

In the classroom, student-centered teaching method should be encouraged. Classroom teaching should take students as the center, to make them communicate more naturally. Strengthening the scene Settings, as much as possible for students, should be encouraged and communication contexts should be also provided. Teachers should help to organize small group activities and assign tasks to students to let them participate in different speech acts and communicative behaviors. Students are required to play different discourse roles. For example, role playing, simulation, theatrical performances and other activities can let students participate in different social roles and speech acts to guide them in different occasions expressed in different ways that they know how to speak and when to talk and say, what and why to say this words, and so on.

\section{Conclusion}

This paper analyzes the reasons for pragmatic failures in cross-cultural communication for the Chinese students and puts forward some reference opinions on the cultivation of pragmatic competence.Admittedly, pragmatic error correction and the cultivation of pragmatic competence are thorny problems and are difficult to handle.In order to make great progress in the innovation and breakthrough in China's foreign language teaching,Chinese educators must make more effort in this field.However, there is still a long way to go for them.

\section{Acknowledgements}

This research was financially supported by the foundation of Education Department of Sichuan Province,China(Grant NO.15SB0255 \&Grant NO.16SB0293) 


\section{References}

[1]. Hu Wenzhong. Communication and Culture. Beijing: Foreign Language Teaching and Research Press, 1994.

[2].Thomas, J. Cross-cultural pragmatic failure. Applied Linguistics, vol. 4, pp. 91-112, 1983.

[3].Leech, G. Principles of Pragmatics. Longman Group Limit. 1983.

[4]. He Ziran. A Survey of Pragramatics. Changsha: Hunan Education Press, 1998.

[5[.Qian Guanlian.Pragmatics in Chinese Culture (Second Edition). Beijing: Tsinghua University Press, 2002.

[6].He Ziran.Pragramatics and English learning.Shanghai: Shanghai Foreign Language Education Press, 1997.

[7]. LiGang. English and intercultural communication strategies sensitive domain communication. Foreign Language, vol. 5, pp. 38-43, 1999.

[8].Lv Wenhua\& Lu Jian Ji. Pragmatic failureof foreigners learning Chinese.Chinese Language Learning, vol. 1, pp. 41-44, 1993.

[9]. LiZheng\&Hu Chunhua. Teaching environment, cognitive context metapragmatic awareness and pragmatic failures.Journal of Zhanjiang Ocean University, vol. 2, pp. 142-146, 2005.

[10]. Bachman, L. Fundamental Considerations in Language Testing. Oxford: Oxford University Press. 1990. 